\title{
Estimation of Stature from Hand and Handprint Measurements among Some Egyptians Using Flatbed Scanner
}

\author{
Nagla M Salama ${ }^{1}$
} ${ }^{1}$ Forensic Medicine and Clinical Toxicology Department, Faculty of Medicine, Alexandria University, Alexandria,
Egypt.

\begin{abstract}
Stature is used for constructing a biological profile that assists with the identification of an individual. Currently, estimation of stature is performed from fleshed and skeletal remains. There has been little attempt to use complete or partial hand impressions left at scene of crime for estimating stature. The aim of the present study, therefore, is to assess the reliability and accuracy of using hand and handprint measurements for the estimation of stature among Egyptian. The study is conducted on 100 males and 100 females in the age group of 21 to 45 years. Stature of each subject is recorded. Following scanning of both hands and converting photos into handprints, eight measurements are taken on each hand and its corresponding print.

Using student $t$. test, significant sex difference are found for all studied parameters where $\mathrm{P} \leq 0.05$ for all measurements. There is no statistically significant difference between left and right hand measurements in both sexes. Hand length showed the highest correlation with stature where $\mathrm{r}=0.517$ in males and 0.781 in females. Correlation coefficients are higher in females than in males as regards all measurements except for hand breadth. All handprint measurements are correlated with stature in both males and females $(\mathrm{P} \leq 0.05)$ except for handprint breadth $(\mathrm{P}=0.38$ in males and 0.183 in females). Stature is strongly correlated with handprint length in females $\mathrm{r}=0.741$ and thumb print length in males $\mathrm{r}=0.514$. Stature prediction accuracy using hand and handprint measurements ranges from 0.978 to 2.98. Multiple regressions reveal nearly the same values obtained by linear regression equations. Comparison between actual stature and the estimated ones showed non-statistical significant differences where $\mathrm{p} \geq 0.05$ for hand and hand print measurements. Hand and handprint measurements are considered a good source for estimating stature in forensic practice among adult Egyptians.
\end{abstract}

Keywords forensic science, forensic anthropology, stature estimation, hand measurements, handprint measurement

\section{Introduction}

Forensic anthropology has a varied array of means and methods to identify unknown commingled human remains (Iscan, 2008, kumar and Chandra, 2006). It is the duty of a medicolegal expert to determine, to the best of his ability, the true identity of unidentified remains. The determination of stature is an important step in the identification of dismembered remains (Jason and Taylor, 1995). Anthropometric techniques are commonly used by anthropologists and adopted by medical scientists to estimate body size for the purpose of identification (Ozaslan et al., 2003).

With the escalating frequency of causalities resulting from mass disasters, identification of victims' biological profile becomes relatively inaccurate. Over the past 20 years, many studies have been conducted in forensic anthropology to assess and estimate stature of different parts of the body to be able to identify victims (Komar and Buikstra, 2008).

There are two major methods of stature estimation in forensic investigations; the anatomical and the mathematical methods. The anatomical method involves the direct reconstruction of stature by measuring and adding together the lengths or heights of a series of contiguous skeletal elements from the skull through the foot. This method has proved to be more accurate to estimate the stature of victims of natural disasters, where the corpses are sometimes unidentifiable (Krishan et al., 2012).

The mathematical method uses regression formulae (or ratios) based on the correlation of individual skeletal elements to measured stature. Long bone regressions produce the most accurate 
estimations, as long bones are the elements most highly correlated to total stature. Human proportions vary systematically between populations and so the most accurate mathematical estimates of stature will be obtained when the population being investigated is as similar as possible in proportions to the population used to create the formulae (Holliday, 1997, Holliday and Ruff, 1997).

Long bones were extensively used for this purpose; yet, long bones are often recovered in various states of fragmentation in forensic and archaeological practice. Therefore, the excellent tables relating long bone measurement to stature do not help. So, the use of other methods become necessary for estimating stature in forensic investigations involving disarticulated and/or incomplete fleshed human remains. (Terazawa et al., 1990).

The aim of the present study was to assess the reliability and accuracy of using anthropometric hand measurements for the estimation of stature among some Egyptian population. Also this study was conducted to evaluate the possible use of handprints measurements for accurate stature estimation as prints are commonly found at crime scenes and to develop regression equations to be used as population - based standards for stature determination.

\section{Subjects and methods}

After obtaining the approval of Ethics Committee, the study was conducted on 200 apparently healthy adults including students and employees (100 males and 100 females) in the age group of 21 to 45 years. All people in this study have attained their maximum growth and therefore attained their maximum length of different body parts (Agnihotri etal., 2008). The study was carried out at Forensic Medicine and Clinical Toxicology Department, Faculty of Medicine, Alexandria University during the academic year 20122013.

Right handed persons (i.e. right hand is the dominant hand) were only included in the present study. Subjects were given an information sheet and were required to sign a consent form before participating in this study.

Stature of each subject was recorded. Height (stature) of the subject was measured in standing posture bared head and foot. The subject was instructed to stand on the board of a standard stadiometer with both feet in close contact with each other, trunk braced along the vertical board, and head oriented in ear-eye plane by keeping the lateral palpebral commissure and the tip of auricle of the pinna in a horizontal plane parallel to the feet. The measurement was taken in centimeters by bringing the horizontal sliding bar to the vertex.

A flatbed scanner (CanoScan LiDE 110) was used to acquire images (400 dpi) of the hands, which were then converted to handprints. To obtain the most accurate approximation of a handprint the scanned images were edited using the Adobe Photoshop1 software package (CS5 extended Version12.); this involves image conversion to grey-scale and adjustments to brightness and contrast. The resultant images of the hands and handprints are then measured using the ruler in the same Photoshop program.

A set of 8 hand dimensions were taken (figure 1).

Each linear measurement were expressed in centimeters.

\section{Exclusion criteria}

- Any apparent hand, limb or vertebral column deformity.

- Left-handed persons since the effect of hand dominance on hand measurements has been suggested (Means and Walters ,1982)

- Related Subjects.

- Poorly defined wrist creases.

\section{Measurements}

Measurements taken on each hand and its corresponding print were as follows:

1- Hand breadth (HB) was measured as a distance between the most lateral point on the head of the 2nd metacarpal to the most medial point on the head of the 5 th metacarpal (Krishan and Sharma ,2007). This requires manual palpation of the hand to locate the required bony anatomy then make a mark for both points before scanning for easy measurements by the photoshop program.

2- The hand length (HL) was measured as straight distance between the midpoint of the distal crease of wrist joint and the most anterior projecting point i.e. tip of middle finger (Agnihotri et al; 2008). 
3- Palm length (PL) was measured as a distance from the mid-point of the distal transverse crease of the wrist to the proximal flexion crease of the middle finger (Kanchan and Rastogi, 2009).

4- Thumb (T); Index (I);-Middle (M); Ring (R) and little (L) Finger lengths were measured as distance between the proximal flexion crease of the finger to the tip of the respective finger

(Robbins, 1986).

The study also included 8 handprints measurements (Figure 2). The definition of the handprint measurements are the same as those provided for the anthropometric measurement of the hand, with the exception of handprint breadth (HPB) and handprint length (HPL) as it is not possible to locate the skin or bone landmarks required to define those measurements. Therefore handprint breadth (HPB) was measured as a distance from the most laterally projected part of the palm print at the 2nd metacarpal to the most medially projected part of the palm print at the distal transverse crease. Handprint length (HPL) was measured as a distance from the baseline of the print (transverse line from the most inferior point of the medial border of the palm to the tip of the middle finger (measurement were modified from a technique based on footprints (Robbins, 1986).

Measurements were repeated twice and the mean was recorded.

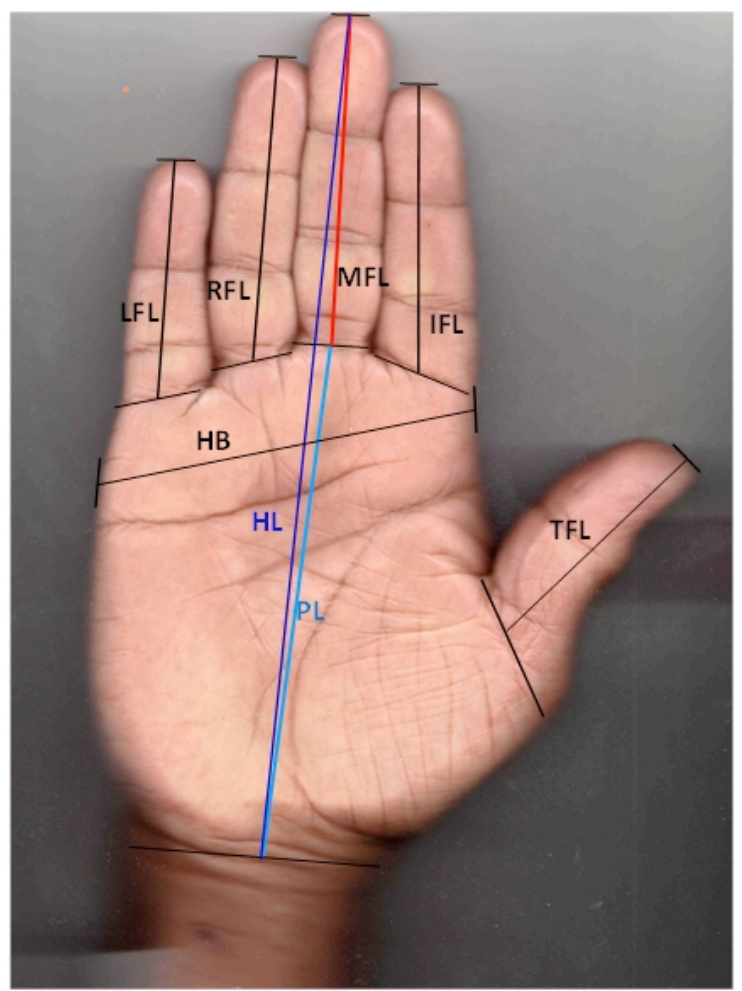

Figure 1: Photograph of the right hand of an adult male showing Hand measurements: hand breadth (HB); hand length (HL); palm length (PL); Middle finger length (MFL); Thumb Finger length (TFL); Index Finger length (IFL); Ring Finger length (RFL) and little Finger Length (LFL). 


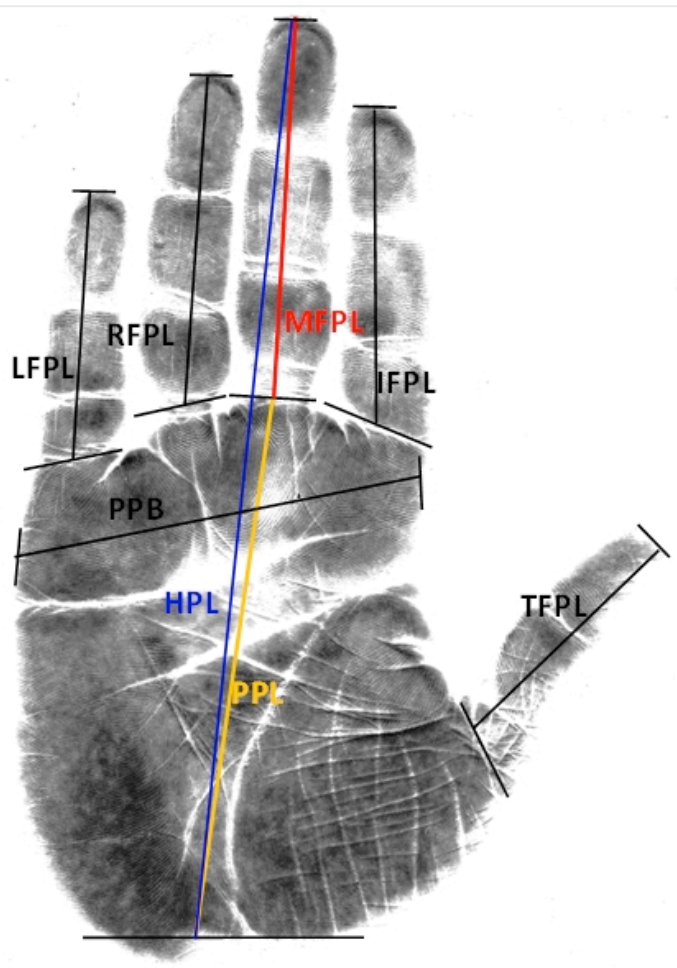

Figure2: Scanned photograph of the right hand of an adult male showing hand print measurements hand print breadth (HPB); hand print length (HPL); palm print length (PPL); Middle finger print length (MFPL); Thumb Finger print length (TFPL); Index Finger print length (IFPL); Ring Finger print length (RFPL) and little Finger print Length (LFPL).

\section{Statistical parameters: (Chan, 2004)}

Data were subjected to statistical analysis using statistical package for social sciences (SPSS) for identifying differences between both sexes regarding the studied parameters. Arithmetic mean, standard deviation, for comparison between two groups t-test was used for parametric data. The correlation coefficient was used to determine the association between two variables. The level of significant was 0.05. Linear regression analysis was performed in which individual variables of hand and handprints measurements were regressed against stature.

Furthermore, multiple regression analyses were also performed in which combinations of these variables were regressed against stature. From the analyses, Pearson's correlation coefficient (r) and standard error of estimate (SEE) were obtained. The SEE predicts the deviations of estimated stature from the actual stature. The reliability of stature estimation from bones by using regression equations is given by standard error of estimate (SEE). A high value of the standard error of estimate (SEE) indicates a low degree of accuracy.

\section{Results}

The descriptive statistics for age and stature, in both males and females are shown in table 1. There was no statistical differences between males and females as regards age where $\mathrm{P}=0.403$. The mean male measured stature was $176.17 \pm 5.80$ and the mean female stature was $161.84 \pm 5.55$. A statistically significant difference was found between males and females as regards stature where $\mathrm{p}=0.0001$
Table (2) shows comparison between right and left hand measurements. There is no statistically significant differences between left and right hand measurements in both gender where $\mathrm{P}>0.05$ for all measurements.

Using student" t" test, significant sex difference are found for all studied parameters between males and females where $\mathrm{P} \leq 0.05$ for all measurements (table 3 ).

Table (4) displays correlation coefficient (r) between stature and different measurements used in this study.

All hand measurements in both males and females are significantly correlated to stature $(\mathrm{P} \leq 0.5)$. It was observed that hand length in males and females showed the highest correlation with stature $(r=0.517$ and 0.781 respectively). This is followed by middle finger length in females $(\mathrm{r}=0.758)$ and thumb length in males $(r=0.516)$.

Correlation coefficients are higher in females than in males as regards all measurements except for hand breadth. On the other hand, table 4 shows that all hand print measurements are correlated with stature in both males and females $(\mathrm{P} \leq 0.05)$ except for handprint breadth $(\mathrm{P}=0.38$ in males and 0.183 in females $)$.

Also it was observed that the variables that are strongly correlated with stature were handprint length followed by index print length in females $(r=0.741$ and 0.653 consequently) while in males the variables most correlated with stature are thumb print length and palmprint length ( $\mathrm{r}=0.514$ and 0.488 consequently).

Table (5) and (6) illustrate the linear regression equations of stature estimation from different hand and hand prints measurements in both 
sexes. The tables also show the standard error of estimation (SEE). For hand measurements, it ranges between 1.3 to 2.16 in males and between 0.978 and 2.45 in females.

For hand prints measurements, the SEE ranges from 1.211 to 2.522 for males and 0.98 and 2.98 for females.

Table (7) and (8) present multiple regression equations for estimation of stature from different combinations of measurements in both sexes.
It is observed that multiple regressions revealed nearly similar value of SEE in both sexes to that obtained by linear regression equations. SEE in males is 1.33 for hand measurements and 1.61 for hand print measurements and in females it is 1.11 for hand measurements and 1.19 for hand print measurements.

Comparison between actual stature and the estimated ones showed non-statistical significant differences where $\mathrm{p} \geq 0.05$ for hand and hand print measurements (Table 9).

Table 1: Student " $t$ " test showing the comparison between males and females $(n=100$ each) regarding the age and the stature.

\begin{tabular}{|l|l|l|l|}
\hline & \multicolumn{1}{|c|}{ Male } & \multicolumn{1}{c|}{ Female } & \multicolumn{1}{c|}{ P } \\
\hline Age (years) & $27.80 \pm 10.48$ & $27.38 \pm 8.08$ & 0.403 \\
\hline Stature $(\mathrm{cm})$ & $176.16 \pm 5.8$ & $161.84 \pm 5.55$ & $0.0001 * *$ \\
\hline$* P \leq 0.05:$ significant $; P \geq 0.05:$ non-significant. \\
$* * P \leq 0.01$ : highly significant.
\end{tabular}

Table 2: Student "t" test showing comparison of different anthropometric parameters between right and left hands among the studied subjects

\begin{tabular}{|l|l|l|l|l|l|l|}
\hline \multirow{2}{*}{ Measurements (cm) } & \multicolumn{2}{|c|}{ Male (n=100) } & \multirow{2}{*}{$\mathbf{p}$} & \multicolumn{2}{c|}{ Female (n=100) } & \multirow{2}{*}{ p } \\
\cline { 2 - 3 } & Right hand & Left hand & & Right hand & Left hand & \\
\hline HB & $9.20 \pm 0.50$ & $9.09 \pm 0.49$ & 0.119 & $8.16 \pm 0.47$ & $8.12 \pm 0.48$ & 0.318 \\
\hline HL & $19.46 \pm 1.00$ & $19.52 \pm 0.80$ & 0.368 & $18.07 \pm 0.87$ & $18.03 \pm 0.88$ & 0.406 \\
\hline PL & $11.54 \pm 1.32$ & $11.38 \pm 0.46$ & 0.179 & $10.30 \pm 0.45$ & $10.31 \pm 0.46$ & 0.448 \\
\hline MFL & $8.34 \pm 0.52$ & $8.34 \pm 0.44$ & 0.489 & $7.88 \pm 0.52$ & $7.86 \pm 0.53$ & 0.404 \\
\hline TFL & $7.17 \pm 0.45$ & $7.14 \pm 0.45$ & 0.362 & $6.70 \pm 1.46$ & $6.52 \pm 0.40$ & 0.185 \\
\hline IFL & $7.46 \pm 0.40$ & $7.43 \pm 0.39$ & 0.319 & $7.04 \pm 0.50$ & $7.01 \pm 0.52$ & 0.379 \\
\hline RFL & $7.81 \pm 0.43$ & $7.78 \pm 0.45$ & 0.352 & $7.28 \pm 0.48$ & $7.26 \pm 0.51$ & 0.438 \\
\hline LFL & $6.40 \pm 0.44$ & $6.35 \pm 0.46$ & 0.275 & $5.89 \pm 0.42$ & $5.88 \pm 0.44$ & 0.444 \\
\hline
\end{tabular}

$* P \leq 0.05$ : significant; $P \geq 0.05:$ non-significant.

Table 3: Student " $t$ " test showing comparison of the hand and handprint measurements among females and males ( $n=100$ each).

\begin{tabular}{|l|l|l|c|}
\hline \multicolumn{1}{|c|}{ Variables } & \multicolumn{1}{c|}{ Male } & \multicolumn{1}{c|}{ Female } & \multirow{2}{*}{ P } \\
\cline { 1 - 2 } Hand measurements (cm) & Mean \pm SD & Mean \pm SD & \\
\hline HB & $9.20 \pm 0.50$ & $8.16 \pm 0.47$ & $0.001^{*}$ \\
\hline HL & $19.46 \pm 1.00$ & $18.07 \pm 0.87$ & $0.001^{*}$ \\
\hline PL & $11.54 \pm 1.32$ & $10.30 \pm 0.45$ & $0.001^{*}$ \\
\hline MFL & $8.34 \pm 0.52$ & $7.88 \pm 0.52$ & $0.001^{*}$ \\
\hline TFL & $7.17 \pm 0.45$ & $6.70 \pm 1.46$ & $0.001^{*}$ \\
\hline IFL & $7.46 \pm 0.40$ & $7.04 \pm 0.50$ & $0.001^{*}$ \\
\hline RFL & $7.81 \pm 0.43$ & $7.28 \pm 0.48$ & $0.001^{*}$ \\
\hline LFL & $6.40 \pm 0.44$ & $5.89 \pm 0.42$ & $0.001^{*}$ \\
\hline Handprint measurements (cm) & & & \\
\hline HPB & $7.96 \pm 0.52$ & $7.06 \pm 0.58$ & $0.001^{*}$ \\
\hline HPL & $18.60 \pm 0.72$ & $17.19 \pm 0.79$ & $0.001^{*}$ \\
\hline PPL & $10.54 \pm 0.50$ & $9.53 \pm 0.40$ & $0.001^{*}$ \\
\hline MFPL & $7.66 \pm 0.49$ & $7.21 \pm 0.48$ & $0.001^{*}$ \\
\hline TFPL & $6.51 \pm 0.47$ & $5.95 \pm 0.39$ & $0.001^{*}$ \\
\hline IFPL & $6.85 \pm 0.44$ & $6.44 \pm 0.49$ & $0.001^{*}$ \\
\hline RFPL & $7.12 \pm 0.40$ & $6.68 \pm 0.51$ & $0.001^{*}$ \\
\hline LFPL & $5.51 \pm 0.45$ & $5.07 \pm 0.41$ & $0.001^{*}$ \\
\hline
\end{tabular}


$* P \leq 0.05$ : significant; $P \geq 0.05$ : non-significant.

Table 4: Pearson's correlation coefficients' analysis between measured stature and different hand and handprints measurements in both sexes $(\mathrm{n}=100 \mathrm{each})$.

\begin{tabular}{|c|c|c|c|c|}
\hline \multirow{2}{*}{$\begin{array}{c}\text { Variables } \\
\text { Hand measurements }(\mathrm{cm})\end{array}$} & \multicolumn{2}{|c|}{ Male } & \multicolumn{2}{|c|}{ Female } \\
\hline & $\mathbf{r}$ & $\mathbf{p}$ & $\mathbf{r}$ & $\mathbf{p}$ \\
\hline HB & 0.372 & $0.04 *$ & 0.306 & $0.02 *$ \\
\hline HL & 0.517 & $0.001 * *$ & 0.781 & $0.001 * *$ \\
\hline $\mathrm{PL}$ & 0.442 & $0.001 * *$ & 0.632 & $0.001 * *$ \\
\hline MFL & 0.400 & $0.002 * *$ & 0.758 & $0.001 * *$ \\
\hline TFL & 0.516 & $0.001 * *$ & 0.642 & $0.001 * *$ \\
\hline IFL & 0.334 & $0.009 * *$ & 0.676 & $0.001 * *$ \\
\hline RFL & 0.371 & $0.004 * *$ & 0.714 & $0.001 * *$ \\
\hline LFL & 0.447 & $0.001 * *$ & 0.610 & $0.001 * *$ \\
\hline \multicolumn{5}{|c|}{ Handprint measurements $(\mathrm{cm})$} \\
\hline $\mathrm{HPB}$ & 0.115 & 0.38 & 0.183 & 0.17 \\
\hline HPL & 0.361 & $0.005 * *$ & 0.741 & $0.001 * *$ \\
\hline PPL & 0.488 & $0.001 * *$ & 0.577 & $0.001 * *$ \\
\hline MFPL & 0.322 & $0.012 *$ & 0.639 & $0.001 * *$ \\
\hline TFPL & 0.514 & $0.001 * *$ & 0.512 & $0.001 * *$ \\
\hline IFPL & 0.309 & $0.016^{*}$ & 0.653 & $0.001 * *$ \\
\hline RFPL & 0.359 & $0.005 * *$ & 0.617 & $0.001 * *$ \\
\hline LFPL & 0.390 & $0.002 * *$ & 0.389 & $0.003 * *$ \\
\hline
\end{tabular}

$* P \leq 0.05$ : significant; $P \geq 0.05:$ non-significant.

$* * P \leq 0.01$ : highly significant.

Table 5: Linear regression equations for stature estimation from different measurements in $\mathbf{m a l e s}(\mathbf{n}=100)$.

\begin{tabular}{|l|l|c|}
\hline \multicolumn{1}{|c|}{ Variables } & \multicolumn{1}{|c|}{ Regression equations } & SEE \\
\cline { 1 - 3 } Hand measurements (cm) & Estimated stature $=157.646+(2.037 * \mathrm{HB})$ & 1.86 \\
\hline HL & Estimated stature $=105.110+(3.641 * \mathrm{HL})$ & 1.442 \\
\hline PL & Estimated stature $=112.959+(5.556 * \mathrm{PL})$ & 1.722 \\
\hline MFL & Estimated stature $=131.822+\left(5.318^{*} \mathrm{MFL}\right)$ & 1.82 \\
\hline TFL & Estimated stature $=129.128+\left(6.588^{*} \mathrm{TFL}\right)$ & 1.301 \\
\hline IFL & Estimated stature $=139.038+(4.996 * \mathrm{FLL})$ & 2.16 \\
\hline RFL & Estimated stature $=139.081+(4.769 * \mathrm{RFL})$ & 1.98 \\
\hline LFL & Estimated stature $=140.055+(5.687 * \mathrm{LFL})$ & 1.52 \\
\hline Hand print measurements $(\mathbf{c m})$ & & \\
\hline HPB & Estimated stature $=165.893+(1.291 * \mathrm{HPB})$ & 2.522 \\
\hline HPL & Estimated stature $=121.957+(2.914 * \mathrm{HPL})$ & 1.425 \\
\hline PPL & Estimated stature $=116.915+(5.621 * \mathrm{PPL})$ & 1.3 \\
\hline MFPL & Estimated stature $=147.161+(3.787 * \mathrm{MFPL})$ & 1.885 \\
\hline TFPL & Estimated stature $=135.021+\left(6.322^{*} \mathrm{TFPL}\right)$ & 1.211 \\
\hline IFPL & Estimated stature $=147.980+\left(4.116^{*} \mathrm{IFPL}\right)$ & 2.132 \\
\hline RFPL & Estimated stature $=138.925+(5.234 * \mathrm{RFPL})$ & 1.782 \\
\hline LFPL & Estimated stature $=148.241+(5.064 * \mathrm{LFPL})$ & 1.33 \\
\hline
\end{tabular}

SEE $=$ Standard Error of Estimate

Table 6: Linear regression equations for stature estimation from different measurements in females $(\mathrm{n}=100)$.

\begin{tabular}{|l|l|l|}
\hline \multicolumn{1}{|c|}{ Variables } & \multicolumn{1}{|c|}{ Regression equations } & \multicolumn{1}{|c|}{ SEE } \\
\cline { 1 - 3 } Hand measurements (cm) & \multicolumn{1}{|c|}{ Estimated stature $=133.347+(3.510 * \mathrm{HB})$} & 2.45 \\
\hline HB & Estimated stature $=72.709+(4.943 * \mathrm{HL})$ & 0.978 \\
\hline HL & Estimated stature $=83.166+(7.630 * \mathrm{PL})$ & 1.422 \\
\hline PL & Estimated stature $=99.826+(7.893 * \mathrm{MFL})$ & 1.06 \\
\hline MFL & Estimated stature $=103.293+(8.980 * \mathrm{TFL})$ & 1.365 \\
\hline TFL & Estimated stature $=111.601+(7.165 * \mathrm{IFL})$ & 1.31 \\
\hline IFL & Estimated stature $=105.238+(7.794 * \mathrm{RFL})$ & 1.22 \\
\hline RFL & Estimated stature $=116.490+(7.715 * \mathrm{LFL})$ & 1.665 \\
\hline LFL & & \\
\hline Handprint measurements $(\mathbf{c m})$ & & \\
\hline HPB & Estimated stature $\mathrm{t}=149.421+(1.760 * \mathrm{HPB})$ & 2.98 \\
\hline
\end{tabular}




\begin{tabular}{|l|l|l|}
\hline HPL & Estimated stature $=72.776+(5.182 * \mathrm{HPL})$ & 0.98 \\
\hline PPL & Estimated stature $=84.806+(8.088 * \mathrm{PPL})$ & 1.44 \\
\hline MFPL & Estimated stature $=108.925+\left(7.338^{*} \mathrm{MFPL}\right)$ & 1.21 \\
\hline TFPL & Estimated stature $=118.589+(7.264 *$ TFPL $)$ & 1.69 \\
\hline IFPL & Estimated stature $=114.342+(7.371 *$ IFPL $)$ & 1.06 \\
\hline RFPL & Estimated stature $=116.772+(6.745 *$ RFPL $)$ & 1.36 \\
\hline LFPL & Estimated stature $=135.128+(5.270 *$ LFPL $)$ & 1.89 \\
\hline
\end{tabular}

$S E E=$ Standard Error of Estimate

Table 7: Multivariate regression analysis equation to determine stature among males (provided the sex is known).

\begin{tabular}{|l|l|l|}
\hline & \multicolumn{1}{|c|}{ Male } & \multicolumn{1}{|c|}{ SEE } \\
\hline $\begin{array}{l}\text { Hand } \\
\text { measurements }\end{array}$ & $\begin{array}{l}\text { Height }=103.285+(0.493 * \mathrm{HB})+(1.385 * \mathrm{HL})+(2.095 * \mathrm{PL})+(1.841 * \mathrm{MFL})+ \\
(4.488 * \mathrm{TFL})-(3.962 * \mathrm{IFL})-(1.937 * \mathrm{RFL})+(2.306 * \mathrm{LFL})\end{array}$ \\
\hline Hand print & $\begin{array}{l}\text { Height }=110.531-(0.455 * \mathrm{HPL})+(3.750 * \mathrm{PPL})(1.095 * \mathrm{MFPL})+(5.596 * \mathrm{TFPL}) \\
(1.304 * \mathrm{IFPL})+(2.731 * \mathrm{RFPL})-(0.717 * \mathrm{LFPL})\end{array}$ & 1.61 \\
\hline
\end{tabular}

SEE $=$ Standard Error of Estimate

Table 8: Multivariate regression analysis equation to determine stature among females (provided the sex is known).

\begin{tabular}{|l|l|c|}
\hline & \multicolumn{1}{|c|}{ Female } & \multicolumn{1}{|c|}{ SEE } \\
\hline $\begin{array}{l}\text { Hand } \\
\text { measurements }\end{array}$ & $\begin{array}{l}\text { Height }=80.306-(3.621 * \mathrm{HB})+(3.055 * \mathrm{HL})+(1.372 * \mathrm{Pl})+(2.374 * \mathrm{MFL})+ \\
(2.894 * \mathrm{TFL})-\left(0.516^{*} \mathrm{IFL}\right)-(0.169 * \mathrm{RFL})+(1.535 * \mathrm{LFL})\end{array}$ & 1.11 \\
\hline Hand print & $\begin{array}{l}\text { Height }=70.624+(2.981 * \mathrm{HPL})+(1.596 * \mathrm{PPL})+(1.596 * \mathrm{MFPL})+(1.683 * \mathrm{TFPL})+ \\
(1.726 * \mathrm{IFPL})-(0.774 * \mathrm{RFPL})-(1.686 * \mathrm{LFPL})\end{array}$ & 1.19 \\
\hline
\end{tabular}

SEE $=$ Standard Error of Estimate

Table 9: Student " $t$ " test showing comparison between measured and estimated stature in both males and females by using hand measurements $(\mathrm{cm})$ and hand print measurements $(\mathrm{cm})$.

\begin{tabular}{|l|c|c|c|c|c|c|}
\hline \multirow{2}{*}{} & \multicolumn{2}{|c|}{ Male (n=100) } & \multicolumn{2}{c|}{ Female (n=100) } \\
\cline { 2 - 3 } \cline { 5 - 6 } & $\begin{array}{c}\text { Measured } \\
\text { stature }\end{array}$ & $\begin{array}{c}\text { Estimated } \\
\text { stature }\end{array}$ & P & $\begin{array}{c}\text { Measured } \\
\text { stature }\end{array}$ & $\begin{array}{c}\text { Estimated } \\
\text { stature }\end{array}$ & $\begin{array}{c}\text { P } \\
\text { Hand measurements } \\
\text { (Mean } \pm \text { SD) }\end{array}$ \\
\hline $\begin{array}{l}\text { Handprint measurements } \\
(\text { Mean } \pm \text { SD) }\end{array}$ & $176.17 \pm 5.8$ & $176 \pm 6.07$ & 0.365 & $161.84 \pm 5.55$ & $159.9 \pm 5.95$ & 0.217 \\
\hline
\end{tabular}

$* P \leq 0.05$ : significant; $P \geq 0.05$ : non-significant.

\section{Discussion}

Stature estimation is an important step in the identification of dismembered remains. Anthropometric techniques are commonly used by anthropologists and adopted by medical scientists to estimate body size for the purpose of identification (Ozaslan et al., 2003, Wilson et al., 2010). Many studies have been conducted to determine stature by taking measurements of long bones and radiographic materials (Madkour and Hamimi, 2009, Mall et al., 2001).

Although some attempts were made for estimating stature from the hands and metacarpal lengths (Abdel-Malek et al., 1990- Habib and Kamal 2010), fewer studies based on hand prints measurements have been reported (Ahemad and Purkait 2011, Ishak et al., 2012).

It is commonly accepted that anthropometric standards vary among different populations and have to be constantly renewed to cope with temporal changes (Mall et al., 2001). So, in spite of the fact that hands and handprints dimensions have been previously used for stature estimation in other studies (Ahemad and Purkait 2011, Ishak et al., 2012), in this study it has been assessed among some adult Egyptians for the first time to develop population based equations for stature estimation.

In the present study, males show higher means values in all measurements i.e. stature, hand length, hand breadth etc. than females. Similar results were obtained by Krishan and Sharma, (2007) where they found a statistically significant difference between mean males and females' hand measurements. These statistically significant differences may be attributed to the early maturity of girls than boys; consequently, the boys have two more years of physical growth.

To test for bilateral asymmetry, it was found that no statistically significant differences between right and left hand measurements. As the difference was found to be insignificant, either left or right hand measurement could be used. Similar results were obtained by Lazenby (2002), who found no dominant effects due to hand sidedness although it has been reported that right hand geometric parameters being larger than those observed on the left hand.

Also Habib and Kamal, (2010) found a statistically non-significant bilateral difference as 
regards hands measurements. In contrast to the findings of the present work, Krishan and Sharma, (2001) found a statistically significant bilateral difference as regards hand length. Also Ishak et al., (2012) found that hand breadth was the only variable in a significant manner between right and left hand measurements. In this study as regards hand measurements, it was observed that stature correlated significantly with all variables in both sexes and it was found that hand length has the strongest correlation to stature. Similar results were obtained by Ishak et al; (2012). Also Habib and Kamal, (2010) found that correlation coefficient of hand length are higher than that of the phalanges in both sexes.

As regards handprints measurements, it was found that handprint length has the strongest correlation to stature in females while thumb print length showed the strongest correlation among males. The findings of the present study were similar to those of Ishak et al., (2012) as regards female handprint length while it was different as regards males where they found that also handprint length has the strongest correlation to stature. Thus, hand length is a good parameter for estimating stature. On the other hand, Ahemad and Purkait, (2011) obtained a statistically insignificant relation between latent hand prints measurements and stature in Indian population.

In this study, the standard error of estimate for all male individual variables ranged from 1.3 to $2.5 \mathrm{~cm}$ and that of all female variables ranged from 0.978 to $2.98 \mathrm{~cm}$. This range is lower than that obtained by Ishak et al; (2012) who recorded an error that ranged from 4.74 to $6.27 \mathrm{~cm}$ for male variables and 5.10 to $6.22 \mathrm{~cm}$ for female variables. This difference could be explained on the basis of regional and racial variations.

Several studies were also conducted on other skeletal bones for the purpose of stature estimation and the SEE was higher than those of the present study as follows:

Mohanty, (1998) studied stature estimation from percutaneous tibial length and a SEE ranged between 2.87 and $3.44 \mathrm{~cm}$ was obtained. The standard error of the estimate obtained in this study was also lower than that obtained in the study of El-Meligy et al., (2006). They obtained an error ranged from 6.51 to $8.24 \mathrm{~cm}$ on using tibial length for formulation of an equation to be used for stature estimation among adult Egyptians. Also they obtained, in the same study, an error ranging from 4.12 to 6.5 upon using bimalleolar breadth for the same purpose. Another study was conducted by Zeybek et al., (2008) on the foot and an error ranging from 3.8 to $10 \mathrm{~cm}$ was obtained.

Madkour and Hamimi, (2009) calculated stature estimation among adult Egyptians from sacral and coccygeal vertebrae with SEE ranging from 3.98 to $6.71 \mathrm{~cm}$ in males and 3.98 to $7.22 \mathrm{~cm}$ in females, whereas Habib and Kamal, (2010) obtained a standard error of estimate (SEE) ranged between \pm 5.30 and \pm 7.27 for males and between \pm 4.54 and \pm 5.48 for females by using hand and phalanges length. Also, Zaher et al.,(2011) studied stature estimation from metacarpal bones of Egyptians with a standard error of estimate (SEE) ranged from $4.53 \mathrm{~cm}$ to $4.71 \mathrm{~cm}$ for males and from $5.45 \mathrm{~cm}$ to $5.87 \mathrm{~cm}$ for females.

In this study, females showed a higher correlation coefficient than males in all studied variables except for hand breadth.

The results of the present work were similar to those obtained by El-Beshlawy and El sheikh, (2003) who studied stature estimation from skull dimensions where females showed higher correlation coefficient than males.

Numerous studies have shown that regressions equations derived from combination of variables present with lower standard error of estimates compared with those obtained from a single variable (Pelin et al., 2005, Dayal et al., 2008). In contrast to these findings, a nearly similar SEE was obtained in the present work using multivariate regression equations for stature estimation from hand and handprint measurements.

Consequently, it was concluded that accurate determination of hand and handprint measurements could be done using scanning and Photoshop programs which are simple, reliable and practical methods. Hand and handprint measurements are considered a good source for estimating stature in forensic practice among adult Egyptians.

\section{Recommendations}

Based on the present study, the following recommendations are proposed:

$$
\begin{aligned}
& \text { Researches on } \\
& \text { population from } \\
& \text { Upper Egypt } \\
& \text { should be done. } \\
& \text { Also the study } \\
& \text { should include } \\
& \text { large number of } \\
& \text { subject with } \\
& \text { different } \\
& \text { occupations. } \\
& \text { Researches on } \\
& \text { other populations } \\
& \text { are also } \\
& \text { recommended to } \\
& \text { confirm whether it } \\
& \text { would be equally } \\
& \text { applicable rer of } \\
& \text { elsewhere. } \\
& \text { The use } \\
& \text { software programs } \\
& \text { for measuring the } \\
& \text { parameters } \\
& \text { better and accurate } \\
& \text { results. }
\end{aligned}
$$

\section{References}

Abdel-Malek AK, Ahmed AM, el-Sharkawi SA and, el-Hamid NA (1990): Prediction of stature from hand measurements, Forensic Sci Int 46; 181-7

Agnihotri AK, Agnihotri S, Jeebun N and Googoolye K (2008): Prediction of stature using hand 
dimensions. J Forensic Legal Med; 15(8):479-82

Ahemad N and Purkait R (2011): Estimation of Stature from Hand Impression: A Non-conventional Approach. J Forensic Sci; 56(3): 706-9

Chan YH (2004): Biostatistics 201: Linear Regression Analysis. Singapore Med J 45(2):55-61

Dayal MR, Steyn M, Kevin L and Kuykendall L. (2008): Stature estimation from bones of South Africans whites. S Afr J Sci; 104:124-8

El- Beshlawy NF and EL-Sheikh ME (2003): An estimation of stature from somatometry of skull among Egyptians. Egypt J Forensic Sci Appl Toxicol 3(1): 1-9

El-Meligy MM, Abdel-Hady RH, Abdel-Maaboud RM and Mohamed ZT (2006): Estimation of human body built in Egyptians. Forensic Sci Int; 159(1):27-31

Habib SR and Kamal NN (2010): Stature estimation from hand and phalanges lengths of Egyptians; J Forensic Leg Med; 17:156-60

Holliday T W. (1997). Body proportions in Late Pleistocene Europe and modern human origins .J hum Evol; 32: 423-47

Holliday TW and Ruff CB (1997): Ecogeographic patterning and stature prediction in fossil hominids: comments on Feldesman and Fountain. Am J phys Anthrop; 103:37-40

Iscan MY (2008): Rise of forensic anthropology. Yearbook Phys Anthropol; 31: 203-30

Ishak NI, Hemya N and Franklin D. (2012): Estimation of stature from hand and handprint dimensions in a Western Australian population. Forensic Sci Int; 216:199.e1-7

Jason DR and Taylor K. (1995). Estimation of stature from the length of cervical, thoracic and lumbar segments of spine in American whites and blacks. J Forensic Sci; 40(1):59-62

Kanchan T and Rastogi P (2009): Sex determination from hand dimensions of North and South Indians. J Forensic Sci; 54: 546-50

Komar DA and Buikstra JE (2008): Forensic Anthropology: Contemporary Theory and Practice, Oxford University Press, New York.

Krishan K and Sharma A (2007): Estimation of stature from dimensions of hands and feet in a North Indian population. J Forensic Leg Med; 14: 327-32

Krishan K and Sharma JC (2001): Bilateral Asymmetry of limb dimensions among Punjabi adolescents. Pb Univ Res J (Sci); 51:79-86

Krishan K, Kanchan T and Sharma A. (2012). Multiplication factor versus regression analysis in stature estimation from hand and foot dimensions. J Forensic and Legal Med; 19:211-4

Kumar J and Chandra L (2006): Estimation of Stature Using Different Facial Measurements Among the Kabui Naga of Imphal Valley, Manipur .Anthropologist; 8(1): 1-3

Lazenby RA (2002): Circumferential variation in human second metacarpal cortical thickness: sex, age and mechanical factors. Anat Rec; 267:154-8

Madkour SA and Hamimi A (2009): Dimensions of sacral and coccygeal vertebrae, a tool for estimation of stature among some adult Egyptians. Ain Shams J Forensic Med Clin Toxicol; 12:13-21

Mall G, Hubig M, Buttner A, Kuznik J, et al. (2001): Sex determination and estimation of stature from the long bones of the arm. Forensic Sci Int; 117: 23-30

Means LW and Walters RE (1982): Sex handedness and asymmetry hand and foot length. Neuropsychological.; 20:715-9

Mohanty NK (1998): Prediction of height from percutaneous tibial length amongst Oriya population. Forensic Sci Int; 98: 137-41

Ozaslan A, Iscan MY, Ozaslan I, Tugcu H, et al. (2003): Estimation of stature from body parts. Forensic Sci Int; 132:40-5

Pelin C, Duyar I, Kayahan AM, Zagyapan R, et al. (2005): Body height estimation based on dimensions of sacral and coccygeal vertebrae. J Forensic Sci; 50(2): 1-4

Robbins LM (1986): Estimating height and weight from size of footprints. J. Forensic Sci; 31; 143-52

Terazawa K, Akabane H, Gotouda H, Mizukami K, et al. (1990): Estimating stature from the length of the lumbar part of the spine in Japanese. Med Sci Law; 30:354-7

Wilson RJ, Herrmann NP and Jantz LM (2010): Evaluation of stature estimation from the database for forensic anthropology. J Forensic Sci; 55:684-9

Zaher JF, El-Ameen NFM, and Seedhom AE (2011): Stature estimation using anthropometric measurements from computed tomography of metacarpal bones among Egyptian population. Egyptian J Forensic Sci; 1:103-8

Zeybek G, Ergur I, and Demiroglu Z (2008): Stature and gender estimation using foot Measurements. Forensic Sci Int; 181 54.e1-5

الملخص العربي

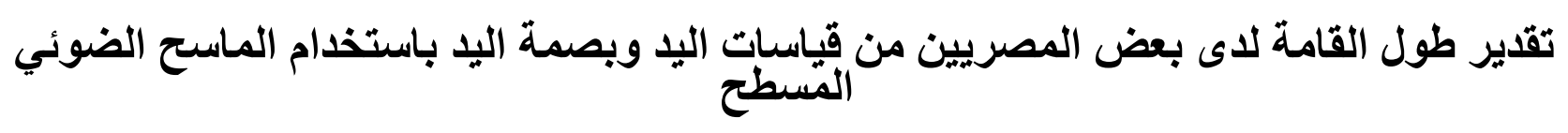

نجلاء سلامة 


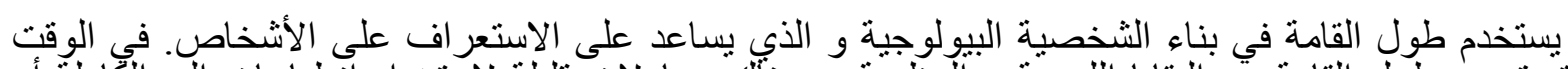

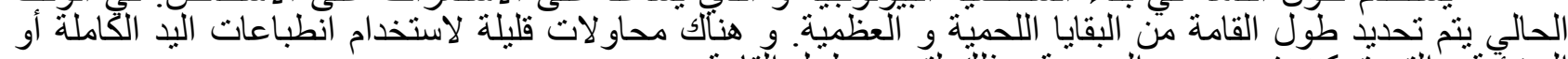

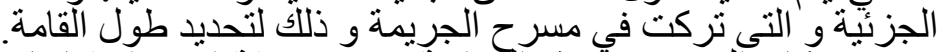

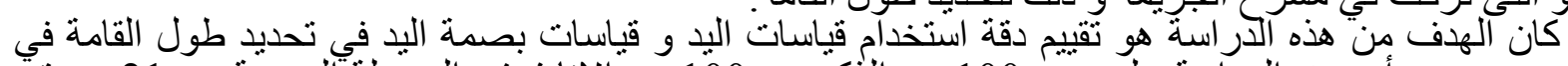

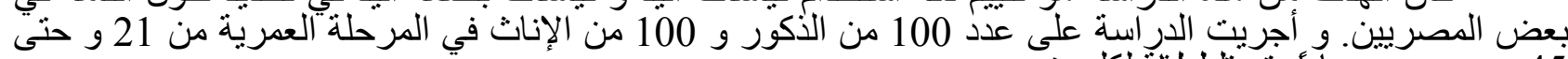

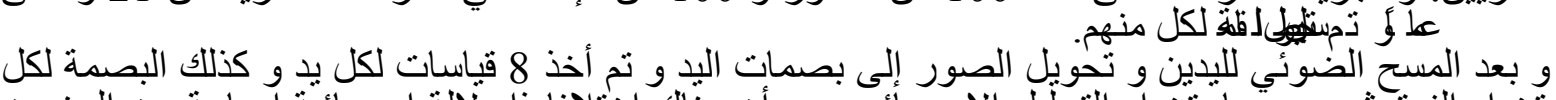

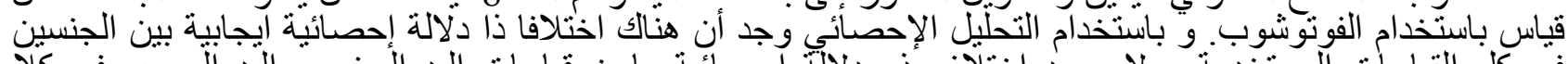

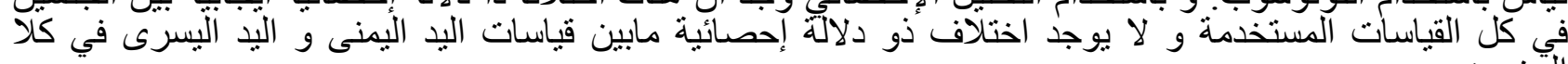

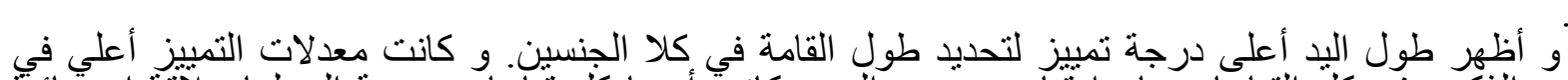

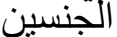

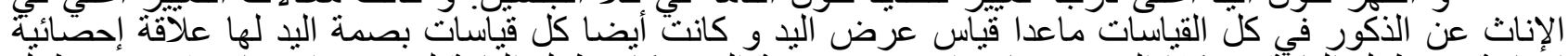

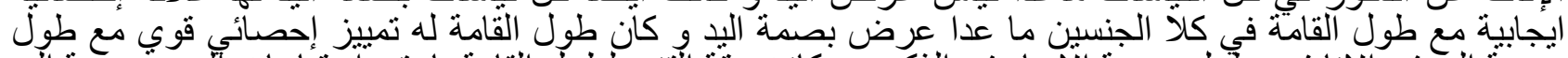

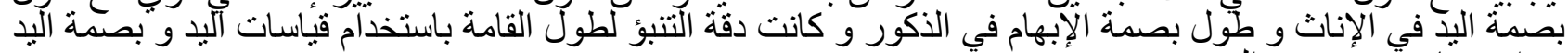

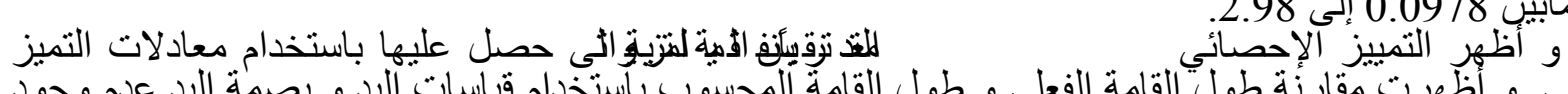
تنتراوح مابين في 0.0978 إلى 2.98.

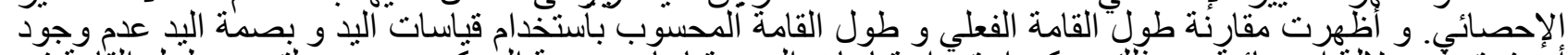

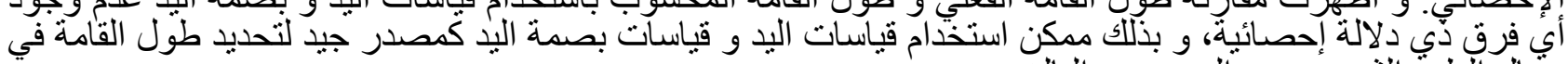

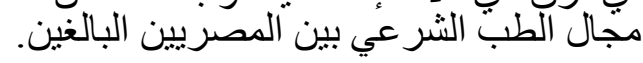

1 قسم الطب الثرعي والسموم الإكلينيكية كلية الطب جامعة الإسكندرية 